\title{
Preparation of Politechnic Sultan Mizan Zainal Abidin (PSMZA) Lecturers in Facing The Industrial Revolution Flow 4.0
}

\author{
Raja Noor Alina Binti Raja Ali ${ }^{1 *}$, Mastura Binti Ibrahim ${ }^{2}$ \\ ${ }^{12}$ Politeknik Sultan Mizan Zainal Abidin \\ $\equiv$ e-mail: alina.ali.poli@1govuc.gov.my
}

\begin{abstract}
Technology development can't be denied a great role and contribution in the life. The world has undergone a technology transition through the first, second and the third revolutions. Every revolutions having its own progress and achievement. Now, the world will facing the new revolutions of the industrial revolutions 4.0, which is based on the emergence of supercomputer, smart robot, also unmanned vehicle and variety technologies. Industrial Revolution 4.0 also pushed up the mobile applications as a medium in every life and it's an inevitable transformation. All parties need to be prepared and adapted to face the challenges of the Industrial Revolutions 4.0 to remain competent. This study aims to identify teaching methods for PSMZA lecturers in the face of the challenges of the Industrial Revolutions 4.0. The study was conducted qualitatively in the form of a document evaluation. Some previous reports were reviewed through findings from the conference and journal, identified as a literature review, data were collected and analyzed using a matrix table. Researchers suggested that polytechnic management set the strategy by increasing the training and seminars on the Industrial Revolution 4.0 and taking other effective measures to ensure that lecturers are prepared to take on the challenge. The PSMZA lecturer is advised to increase knowledge in information technology, further reading and training remain competent in the current Industrial Revolution 4.0.
\end{abstract}

Keywords:Industrial Revolutions 4.0; Transformation; Competent

\section{Persediaan Tenaga Pengajar Politeknik Sultan Mizan Zainal Abidin (PSMZA) di dalam Mengharungi Arus Revolusi Indusri 4.0}

\begin{abstract}
Pembangunan teknologi tidak boleh dinafikan peranan dan sumbangan besar dalam kehidupan. Dunia telah melalui peralihan teknologi melalui revolusi pertama, kedua dan ketiga. Setiap revolusi mempunyai kemajuan dan pencapaian sendiri. Sekarang, dunia akan menghadapi revolusi baru revolusi industri 4.0, yang didasarkan pada kemunculan superkomputer, robot pintar, juga kenderaan tanpa kenderaan dan pelbagai teknologi. Revolusi Perindustrian 4.0 juga meningkatkan aplikasi mudah alih sebagai medium dalam setiap kehidupan dan ia adalah satu transformasi yang tidak dapat dielakkan. Semua pihak perlu bersedia dan disesuaikan untuk menghadapi cabaran Revolusi Perindustrian 4.0 untuk kekal kompeten. Kajian ini bertujuan untuk mengenal pasti kaedah pengajaran pensyarah PSMZA dalam menghadapi cabaran Revolusi Perindustrian 4.0. Kajian ini dijalankan secara kualitatif dalam bentuk penilaian dokumen. Beberapa laporan terdahulu dikaji semula melalui penemuan dari persidangan dan jurnal, yang dikenalpasti sebagai
\end{abstract}


kajian literatur, data dikumpulkan dan dianalisis dengan menggunakan jadual matriks. Para penyelidik mencadangkan pengurusan politeknik menetapkan strategi dengan meningkatkan latihan dan seminar mengenai Revolusi Perindustrian 4.0 dan mengambil langkah-langkah lain yang berkesan untuk memastikan pensyarah bersedia untuk menghadapi cabaran tersebut. Pensyarah PSMZA dinasihatkan untuk meningkatkan pengetahuan dalam teknologi maklumat, bacaan dan latihan terus kekal kompeten dalam Revolusi Perindustrian semasa 4.0.

Keywords:Revolusi Perindustrian 4.0; Transformasi; Kompeten

This is an open access article distributed under the Creative Commons 4.0 Attribution License, which permits unrestricted use, distribution, and reproduction in any medium, provided the original work is properly cited. (C2018 by author

\section{PENGENALAN}

Istilah Revolusi Industri diperkenalkan oleh ahli sejarah terkenal, Arnold Toynbee (1889-1975). Menurut "Kamus Dewan Edisi Keempat" terbitan Dewan Bahasa dan Pustaka (DBP) revolusi memberi maksud perubahan yang menyeluruh dan mendadak, terutamanya dari segi cara berfikir, bertindak dan sebagainya. Sebelum wujudnya era revolusi industri, sistem ekonomi dunia bergantung kepada ekonomi berasaskan pertanian. Arus revolusi perindustrian telah berlaku sebanyak 3 kali termasuklah Revolusi Industri 1.0, 2.0 dan 3.0. Revolusi Industri 1.0 bermula di Britain pada pertengahan abad ke-18 (17601840) yang memperlihatkan penciptaan mesin-mesin bagi memudahkan pekerjaan dan dalam masa yang sama menambahkan produktiviti kerja. Penciptaan mesin-mesin yang menggunakan kuasa enjin wap dan tenaga air sekaligus telah meningkatkan pengeluaran secara mendadak dan berlipat-ganda. Revolusi Industri 1.0 ini telah menular ke seluruh Eropah dan Amerika Utara.

Pada tahun 1870-1940, Revolusi Industri 2.0 pula muncul dan ditandai dengan penggunaan kuasa elektrik sebagai sumber tenaga yang lebih murah dan cekap. Penggunaan elektrik sekaligus mendorong penciptaan baru seperti telefon, telegraf, penggunaan besi dan baja dalam skala besar serta meluasnya penggunaan mesin-mesin di kilang. Pada tahun 1969, Revolusi Industri 3.0 pula muncul dengan penggunaan menggunakan komputer dan teknologi maklumat. Di peringkat akhir revolusi ketiga muncul pula teknologi automasi dimana berkembangnya teknologi tanpa melibatkan manusia secara langsung. Mesin dan jentera ini mempunya keupayaan melakukan kerja sepertimana yang telah diprogramkan. Secara umumnya, Industri 4.0 pertama kali bermula dari Hannover Fair, Jerman, tahun 2011. Ia merupakan pameran teknologi industri dan perdagangan terbesar di Jerman. Pada akhir 2013, Revolusi Industri 4.0 muncul dan merupakan kesinambungan daripada peningkatan automosi beserta rangkaian Internet dan proses-proses fizikal lain. Teknologi baru tersebut termasuklah automasi, simulasi, analisis dan big data, penggunaan robotik, cloud dan Internet of Things (IoT). Klaus Schwab, menerusi bukunya The Fourth Industrial Revolution menjelaskan Industri 4.0 mengubah cara kita bekerja dan hidup. Ia melibatkan teknologi automasi dan secara tidak langsung memberi cabaran baru kepada semua bidang di negara ini termasuklah bidang pendidikan.

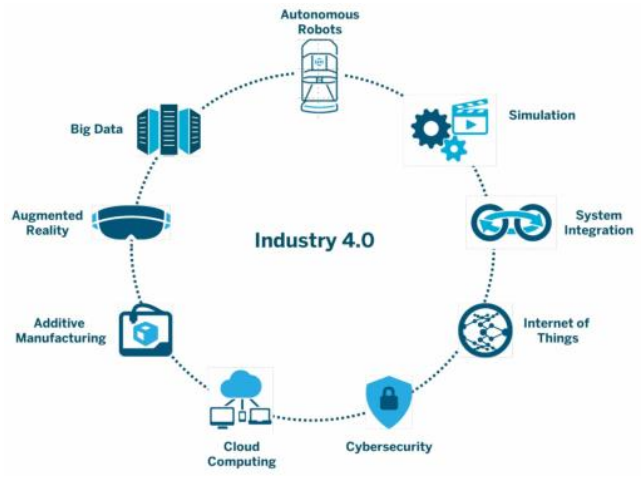

Rajah 1

(Putri Agus, 2018) 
Bidang pendidikan negara perlu melakukan perubahan seiring dengan transformasi digital untuk kekal kompeten dan terus berdaya saing. Politeknik Sultan Mizan Zainal Abidn turut perlu mengubah proses pengajaran dan pembelajaran untuk menghadapi cabaran Revolusi Industri 4.0. Perubahan ini merangkumi aspek-aspek ruang pembelajaran, kaedah pengajaran, fasiliti, kurikulum yang lebih organik dan penggunaan teknologi terkini. Diantara lain ialah melalui kaedah baru pengajaran dimana pelajar belajar tanpa syarahan di bilik kuliah, cara pentaksiran juga berubah di mana terdapat kebanyakan kursus atau subjek tidak memerlukan peperiksaan. Abdullah, M (2018) menyatakan bahawa menurut Laporan Digital 2017, setelah lebih daripada 25 tahun sejak penghasilan World Wide Web oleh Sir Timothy John Berners-Lee, internet kini telah menjadi sebahagian daripada kehidupan harian manusia di dalam hubungan social. Ianya turut memainkan peranan yang penting terhadap pembangunan ekonomi, politik dan aspek-aspek lain. Menurut Zakaria, M.R (2018), pendidikan memainkan peranan amat penting dalam Revolusi Industri 4.0. Maka, pendekatan pembelajaran perlu berubah seiring dengan pembangunan automasi sebagai strategi menghadapi persaingan untuk kekal relevan kerana pekerjaan juga akan turut berubah.

\section{Pernyataan Masalah}

Revolusi Industri 4.0 yang melibatkan teknologi automasi memberi cabaran baru kepada semua sektor di negara ini. Revolusi ini menandakan kemunculan sistem fizikal siber menjurus ke arah pendigitalan sejajar dengan keperluan semasa dalam pelbagai sektor. Sehubungan dengan itu, persediaan yang rapi daripada semua sektor perlu dilakukan agar seiring dengan teknologi kini. Sektor pendidikan juga tidak ketinggalan bagi menempuhi cabaran Revolusi Industri 4.0. Sebagai institusi pendidikan, PSMZA turut terkesan dalam mendepani cabaran ini. Persedian yang rapi perlu dirancang dari segi fasiliti, tenaga pengajar dan stakeholders bagi menyahut cabaran ini. Pendedahan terhadap Revolusi Industri 4.0 kepada tenaga pengajar dan warga PSMZA perlu ditekankan selaras dengan transformasi pendidikan tinggi iaitu Pelan Pembangunan Pendidikan Malaysia (Pendidikan Tinggi). Selain itu, kaedah pengajaran yang seiring Revolusi Industri 4.0 harus dipraktikkan dengan meluas.

\section{Objektif Kajian}

Objektif kajian ini adalah;

1. Mendedahkan kepada tenaga pengajar tentang Revolusi Industri 4.0 dalam bidang pendidikan.

2. Memberi pendedahan berkenaan transformasi pendidikan yang seiring dengan keperluan semasa.

3. Menggalakkan penggunaan kaedah pengajaran yang seiring dengan Revolusi Industri 4.0

\section{Persoalan Kajian}

Sektor pendidikan juga perlu bersedia dengan cabaran ini bagi memastikan pelajar yang dihasilkan kompeten dan mempunyai semua kemahiran sebelum melangkah kaki ke alam pekerjaan. Bayangkan sekiranya kemahiran dan pengetahuan kita pada hari ini sudah tidak releven pada 30 tahun akan datang. Bayangkan juga sekiranya cara pendekatan yang digunakan dikatakan telah lapuk dan tidak terkini jika dibandingkan dengan individu berkemahiran tinggi, kreatif dan mempunyai pemikiran kritis. Pernahkah kita terfikir sekiranya graduan yang dihasilkan gagal memenuhi pasaran kerja seterusnya menyebabkan kadar pengangguran meningkat. Bagaimana pula sekiranya teknologi automasi ini diaplikasikan sepenuhnya oleh robot. Jadi, di manakah peranan kita sebagai pendidik. 


\section{LITERATUR REVIEW}

\section{Pembangunan sumber manusia}

Pendidikan merupakan satu wadah penting dalam menjana anjakan paradigma dalam diri setiap individu dan ia juga memainkan peranan penting di dalam melahirkan sumber manusia yag berilmu dan bermanfaat bagi negara. Menurut Preston dan Elo (1996), pendidikan berkualiti sangat efektif bagi menentang kemiskinan, membina demokrasi dan membentuk masyarakat yang sejahtera. Oleh yang demikian, dengan perkembangan teknologi masa kini, seharusnya pendidik serta pelajar perlu peka kepada kehendak perubahan teknologi tersebut agar ilmu yang dimiliki kekal relevan.

Menurut Mohamed Makhbul, Z. K (2018), perubahan yang berlaku rentetan daripada Industri Revolusi 4.0 memerlukan sumber manusia berpengetahuan dan berkemahiran tinggi. Ini bagi memastikan mereka berdaya saing dan merupakan pelapis yang mewarisi pentadbiran organisasi dan negara. Menurut Samah, R (2018) pula, graduan boleh ketinggalan sekiranya tidak bersedia di dalam pasaran kerjaya yang berasaskan penggunaan jentera dan teknologi. Ianya termasuklah adaptasi permainan maya, hologram, realiti maya (VR), realiti berperantara (AR), pengguna visual, simulasi serta penerokaan internet. Menurut Shaari M. N (2017), Internet of Things (IoT) secara umumnya bermaksud idea menghubungkan semua benda dan perkara dengan internet. Menurut Zakaria, M. R (2018), tiga kemahiran paling relevan dalam Industri 4.0 ialah kemahiran belajar iaitu belajar kendiri, pelbagai bidang dan kemahiran digital; kemahiran berfikir yang terdiri daripada berfikir secara kreatif, berdaya tahan, semangat ingin tahu dan menyelesaikan masalah. Selain daripada itu juga, kemahiran insaniah seperti etika dan komunikasi turut diperlukan bagi membentuk pelajar yang seimbang.

\section{Kemahiran masa depan}

Pendidikan tinggi perlulah mempersiapkan graduan yang berkemahiran bagi menempuh cabaran Revolusi Industri 4.0. Pendidikan di institusi tinggi dirancang bagi bergerak seiring dengan Pelan Pembangunan Pendidikan Malaysia (Pendidikan Tinggi) atau singkatannya, PPM (PT) 2015-2025 seperti yang ditunjukkan Rajah 2. Diantaranya ialah dengan memperkenalkan sistem Purata Nilai Gred Kumulatif Bersepadu (iCGPA) yang menilai pelajar dari segi akademik dan aktiviti kokurikulum, sosial serta sukarela. Ia telah diiktiraf sebagai kaedah pentaksiran komprehensif yang mampu melahirkan graduan holistik, berciri keusahawanan dan seimbang. Pengajar pendidikan tinggi juga perlu bersedia dengan pelbagai keadah pengajaran terkini seperti program Massive Open Online Courses(MOOC), program CEO@Faculty dan Program Work Based Learning (WBL). Pendekatan perlaksanaan pendidikan dan latihan di institusi pendidikan tinggi dan politeknik perlu berubah bagi menyahut cabaran dan merebut peluang rentetan perkembangan teknologi digital.

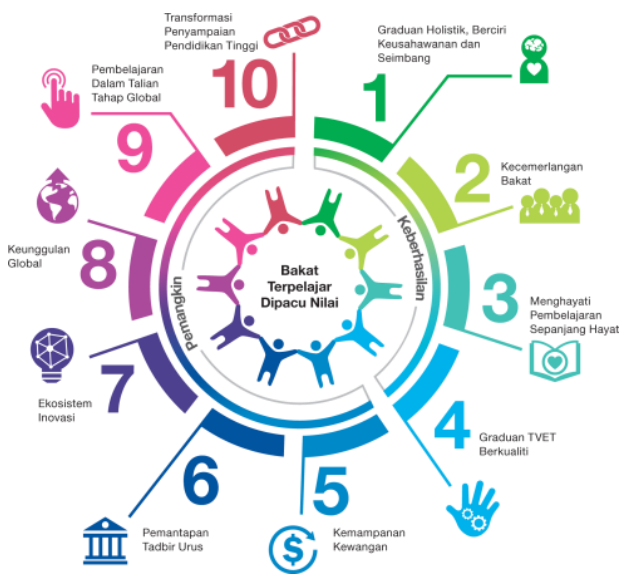

Rajah 2 
Seperti diramalkan Klaus Schwab, pengasas World Economic Forum, Revolusi Industri 4.0 akan mengubah kelaziman di dalam perniagaan dan jenis kemahiran yang diperlukan untuk pekerjaan masa depan.Pihak industri dan masyarakat memainkan peranan yang penting di dalam pembangunan pelajar melalui sokongan aktiviti pembelajaran secara langsung mahupun tidak termasuklah memberi peluang pelajar menimba pengalaman persekitaran kerja sebenar di syarikat. Strategi-strategi pembelajaran berasaskan kerja (WBL) merupakan satu bahagian yang penting dalam pembangunan masa depan dan berterusan bagi tenaga kerja sedia ada (Tom Lemanski, Ruth Mewis dan Tina Overton, 2011). Menurut Sodiechowska dan Maisch, 2006menyatakan bahawa Work based learning (WBL) boleh didefinasikan sebagai; '.. di mana pelajar ialah pekerja sepenuh masa yang telah dirancang untuk belajar di dalam tempat kerja dan memenuhi keperluan pembelajaran kakitangan dan matlamat organisasi'

Menurut Mohd Yusof , M. F (2017) bagi mendepani cabaran Revolusi Industri 4.0, pelajar di universiti mesti keluar daripada kebiasaan. Forum Ekonomi Dunia (WEF) turut menggariskan pentingnya penguasaan elemen 4C iaitu Critical Thinking \& Problem Solving, Communication, Collaboration dan Creativity pada semua peringkat pengajian, termasuk di menara gading.

\section{Massive Open Online Courses (MOOC)}

Massive Open Online Course (MOOC) terkenal sebagai satu kaedah pembelajaran terkini di seluruh dunia (McGuire, 2014).Di Malaysia, MOOC dibangunkan pada sekitar tahun 2014 oleh setiap bahagian e-pembelajaran universiti awam hasil cadangan daripada pihak Kementarian Pendidikan Malaysia.MOOC adalah pembelajaran atas talian yang boleh diakses oleh setiap orang di seluruh pelusuk dunia dengan percuma (Carroll, 2011; Epelboin, 2013; Abeera \& Miri, 2014; Khalil \& Ebner, 2015; Chua et al., 2015; Alshehri, 2015). Menurut Watted Abeera, Barak Miria (2014), MOOC menyediakan akses percuma kepada bahan-bahan pengajaran yang berkualiti tinggi. MOOC menawarkan sumber pembelajaran secara terbuka kepada seluruh lapisan masyarakat sedunia dan menawarkan video pembelajaran, kuiz dan ujian secara atas talian serta kerja kursus secara individu dan berkumpulan.

Perkongsian ilmu secara global dan terbuka ini disambut baik oleh pelajar awam tempatan. Menurut Raja Rahim, R.N (2017) memetik ucapan mantan Menteri Pendidikan Tinggi Malaysia, Datuk Seri Idris Jusoh sempena Karnival Pembelajaran Maya Universiti Antarabangsa 2017 (IUCEL 2017) di Universiti Sains Islam Malaysia (USIM) menyatakan bahawa secara keseluruhannya, seramai 600,000 penuntut dalam dan luar negara mengikuti 450 kursus yang ditawarkan di universiti awam dan swasta serta politeknik atau kolej komuniti melalui MOOC. Ia merupakan satu pendekatan yang seiring dengan Pembelajaran Dalam Talian Tahap Global seperti digariskan dalam Pelan Pembangunan Pendidikan Malaysia 2015-2025 (Pendidikan Tinggi). Menurut Adzhar, H ; Khalid, F; Abdul Karim, A (2017) menyatakan Jansen, (2016) mengulas bahawa konsep MOOC adalah terdiri daripada sumber pendidikan terbuka atau Open Educational Resources (OER) Pembelajaran Abad ke-21 : Trend Integrasi Teknologi 180. MOOC mula diperkenalkan oleh Dave Cormier dari University of Prince Edward Island pada tahun 2008 dan Bryan Alexender dari National Institute for Technology in Liberal Education (Chirs, 2013). MOOC direka secara terbuka dan menggalakkan perkongsian ilmu secara meluas. Ia merupakan platform yang yang baik untuk membantu pendidik meneroka kaedah baru pengajaran secara atas talian. Konteks pedagogi MOOC lebih menekankan kepada konsep pembelajaran kendiri yang menekankan pembelajaran fleksibel yang berasaskan hasil pembelajaran di mana fokus adalah kepada pencapaian dan hasil pembelajaran pelajar (Garis Panduan Pembangunan \& Penyampaian MOOC Malaysia, 2016). 

typically broken into small chunks (two to ten minutes). Other media (YouTube clips, etc.) is often integrated into the lecture as well. or recommended. These activities could take the form of questions, a small-scale project (such as developing one or two lines of programming code), or redirecting to an outside source of information or experience.

Course-Specific Forums: Since you can't interact with other students or your professor in person, it's important to have a way to ask questions and get other perspectives online. Our top three recommended platforms integrate a forum into each course that allows for questions to be quickly addressed by the community or moderators.

Sectional or Weekly Organization: Most MOOCs are organized into a series of sections or weeks (depending on whether the course is scheduled or a "learn-at-your-own-pace" course)

\footnotetext{
Sectional Test or Project: You can usually expect there to be some sort of project or test at the end of each section to reinforce what was learned in that section or week.

Final Examination or Project: There is typically some sort of final examina tion or project that measures whether the student has an acceptable grasp on the skills and concepts presented in the course. Most MOOCs are "pass/fail" meaning that there isn't a letter grade given out, and some give you the option to keep trying until you succeed.
}

\section{Rajah 3}

(Reviews.com)

\section{Flipped Classroom}

Flipped Classroom merupakan model pendekatan pengajaran yang menukarkan masa kuliah di dalam kelas kepada kuliah melalui video di luar kelas. Maka waktu kelas pula digunakan sepenuhnya untuk tutorial dan pengukuhan kepada pelajar secara individu. Flipped classroom (Baker, 2000) atau dikenali sebagai inverted classroom (Lage et al., 2000) merupakan salah satu kaedah pembelajaran berpusatkan pelajar yang telah mula diperkenalkan pada tahun 2000 kepada pelajar universiti . Menurut Bergmann dan Samms (2009), kaedah ini mula mendapat perhatian setelah diaplikasi oleh dua orang guru sekolah iaitu menerusi penggunaan video dan aktiviti pembelajaran dalam talian.

Menurut A.Rahman, A; Aris, B; Mohamed, H; Mohd Zaid, N dan Abdullah, Z (2014) menyatakan bahawa Herreid dan A.Schiller (2012) kaedah flipped classroom mula dilaksanakan di peringkat universiti dalam bidang Sains, Teknologi, Kejuruteraan dan Matematik atau STEM (Herreid and Schiller, 2012; Hamdan et al., 2013. Flipped Classroom berkembang pesat dengan dengan wujudnya Khan Academy (Hilmi, 2016). Ia merupakan pendekatan pembelajaran yang menggalakkan pelajar berinteraksi secara aktif dengan pengajar dan juga pelajar lain. Proses pengajaran dan pembelajaran juga adalah lebih berpusat dan menggalakkan 'independent learning'. Secara tidak langsung, ianya akan menggalakkan pelajar untuk lebih berdikari dan berupaya untuk bekerja secara individu. 


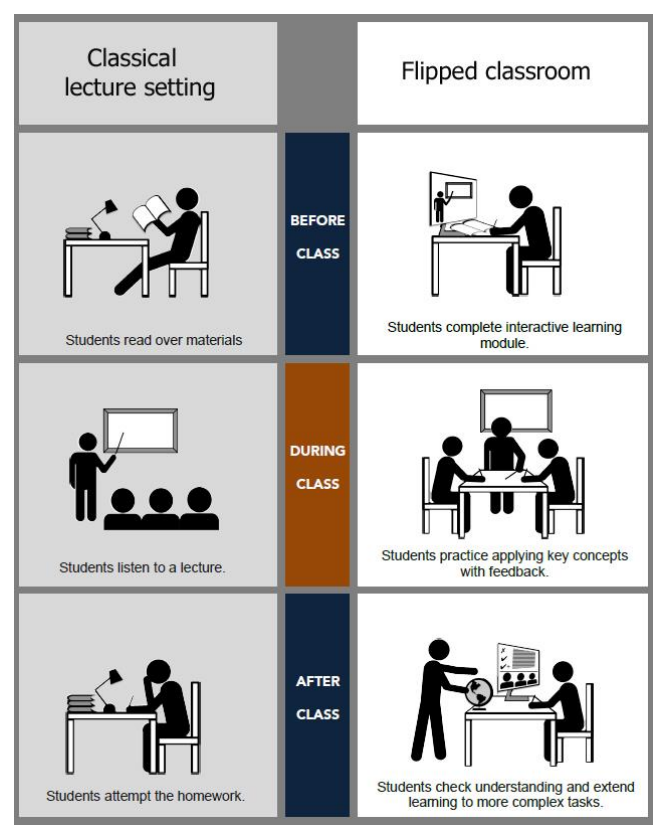

Rajah 4

(Azrina Sazali, 2015)

\section{Membudayakan inovasi}

Inovasi digital perlu dipergiatkan di dalam bidang pendidikan. Menurut Pelan Strategik Kementerian Sains,Teknologi Dan Inovasi (MOSTI) 2016-2020, inovasi perlu diperkasakan seiring dengan Dasar Sains, Teknologi dan Inovasi Negara (DSTIN) yang menetapkan hala tuju baru dalam bidang sains, teknologi dan inovasi (STI) bagi mentransformasikan Malaysia ke arah sebuah negara yang lebih kompeten dan kompetitif sekaligus bersedia mengharungi arus Revolusi Industri 4.0.

Menurut Kamus Dewan Bahasa dan Pustaka Edisi keempat, inovasi didefinasikan sebagai sesuatu yang baru diperkenalkan seperti kaedah, sistem, adat dan lain-lain lagi yang baru. Inovasi adalah merupakan suatu idea, hal-hal yang praktikal, atau kaedah, atau cara, atau barang-barang yang dapat diamati atau dirasakan sebagai sesuatu yang baru bagi manusia bagi menyelesaikan masalah tertentu (Rinoto Rin, 2014). Sebuah idea, gagasan, amalan atau sesuatu perkara yang diterima sebagai satu reka cipta yang baru oleh seseorang atau kelompok masyarakat untuk dipraktikkan (Everett M.Rogers,1983). Inovasi merupakan kebolehan untuk mengaplikasikan penyelesaian kreatif kepada masalah atau peluang untuk meningkatkan atau penggayaan kehidupan manusia. (Zimmerer \& Scarborough, 2005)

Tujuan inovasi adalah mengurangkan ralat dalam produk sedia ada, meningkatkan kualiti, mencipta pasaran baharu, memperluas jangkauan produk, mengurangkan kos tenaga kerja, meningkatkan produktiviti, mengurangkan penggunaan tenaga serta menjimatkan kos (Amy Syahida, 2018). Inovasi digital pula berkait rapat dengan IoT yang merangkumi sistem lebih besar seperti pejabat dan rumah pintar dan kemudahan infrastruktur yang lain. Semua pengesan akan diletakkan untuk mengenal pasti perubahan yang berlaku dan semua data tersebut akan dikumpulkan ke pangkalan data awan (cloud database). Data tersebut dianalisis dan tindakan secara automasi dilakukan secara tidak langsung akan pengguna (Shaari, M.N, 2017).

Budaya inovasi dalam sesebuah institusi pendidikan amat penting dalam menghadapi Revolusi Industri 4.0. Perkembangan teknologi yang pesat perlu disahut oleh mahasiswa dengan berusaha menyiapkan diri dalam menghadapai cabaran pada masa hadapan. Era IR4.0 lebih menumpukan penggunakaan data secara globalisasi, pembinaan robot genius, pemanduan secara kendiri serta neuro- 
teknologi otak dan pembaikian genetik. Kesannya, penglibatan manusia di dalam indusri semakin mengecil. Bagi mengimbangkannya, mahasiswa perlu lebih bersifat kreatif dan inovatif dalam mencipta sesuatu. Peranan mahasiswa sebagai insan amat penting dalam proses penyelesaian masalah walaupun mesin telah menggantikan manusia dalam dunia industri. Pendidikan berasaskan inovasi ini boleh diterjemahkan melalui inisiatif projek pelajar yang bercirikan inter-disiplin dengan sekurang-kurangnya $30 \%$ daripada jumlah bilangan projek yang dibangunkan mengikut program mempunyai ciri yang dinyatakan. Projek yang dihasilkan perlu mengintegrasikan dua atau lebih disiplin dalam penyelidikan.

Ahmad, R; Hassan, H; Aizatul Akma (2016) menyatakan perkembangan inovasi teknologi digital seperti facebook, Youtube, Twitter serta kemunculan produk seperti iPhone, Android juga telah mengubah kehidupan masyarakat menjadi semakin mencabar serta berdaya saing. Reformasi kepada kepesatan perkembangan teknologi ini turut dikecapi oleh golongan mahasiswa. Maklumat berada di hujung jarimenjadikan mahasiswa seorang yang mampu untuk berdikari, berinovatif dan kreatif. Menurut Richard Florida (2005), institusi pengajian tinggi merupakan sebagai pusat inovasi, penyelidikan dan penyumbang kepada idea dan rekacipta baharu yang menyumbang kepada produktiviti dan perkembangan ekonomi.

\section{Cabaran persekitaran organisasi}

Revolusi Industri 4.0 datang dengan pelbagai cabaran yang perlu dilalui oleh organisasi untuk kekal kompeten di dalam arus perdana. Persekitaran organisasi PSMZA yang mantap perlu dan dalam masa yang sama bersedia didalam peralihan paradigma kepada kecekapan dalam semua peringkat pengurusan. Ini adalah bagi memastikan agar tidak ketinggalan di dalam arus Revolusi Industri 4.0. Bagi Darmin, tidak ada zon selesa pada revolusi ini, karena keadaan teknologi dunia terlalu cepat berubah.

Menurut Ahmad, A. (2017) menyatakan bahawaForum Ekonomi Dunia (WEF) menggariskan pentingnya penguasaan elemen 4C iaitu Critical Thinking \& Problem Solving, Communication, Collaboration dan Creativity pada semua peringkat pengajian termasuk di institusi tinggi. Para pelajar yang bakal dilahirkan mestilah mempunyai kemahiran penyelesaian masalah kompleks, cemerlang di dalam kemahiran berkomunikasi secara verbal dan bertulis, berkepimpinan dan mempunyai keyakinan diri yang tinggi serta sentiasa kreatif dan bijak memanfaatkan semua peluang yang ada. Sehubungan dengan itu, tenaga pengajar terlebih dahulu perlu mempersiapkan diri dengan semua nilai-nilai teras tersebut kerana mereka merupakan inspirasi kepada pelajar. Para pendidik juga perlu bersedia untuk melakukan inovasi pengajaran dan pembelajaran.

Menurut Yunus, Y (2017) kerajaan Malaysia komited membudayakan inovasi digital melalui Pelan Strategik ICT Sektor Awam 2016-2020 dan Pelan Pendigitalan Penyampaian Perkhidmatan Kerajaan melalui Teras Strategik Pendigitalan Mengurus bagi merealisasikan nilai data secara cekap dan holistik. Melaluinya, perkongsian data merentasi agensi sektor awam dapat diperkukuhkan.

\section{METODOLOGI}

Tujuan utamapenyelidikan adalah untuk mengenalpasti persediaan tenaga pengajar di dalam mengharungi arus revolusi indusri 4.0. Bagi mencapai tujuan ini, kajian dijalankan secara kualitatifnya dalam bentuk satu penilaian dokumen. Hasan, A; Tuan Mohd Yasin, S.N dan Mohd Yunus, M. F (2016), menyatakan bahawa menurut (Strauss dan Corbin, 1990) beberapa laporan terdahulu perlu dikaji melalui dapatan daripada persidangan dan jurnal telah dikenalipasti sebagai tinjauan literatur dan data yang dikumpul akan dianalisis dengan menggunakan satu meja matriks. Berdasarkan Sallabas (2013) ; Best dan Kahn (1998), kaedah penilaian dokumen ialah alat paling sesuai akan mengumpul maklumat dalam satu kajian kualitatif. 


\section{DAPATAN KAJIAN DAN PERBINCANGAN}

Cabaran yang perlu ditempuhi oleh tenaga pengajar masakini adalah berbeza dengan zaman lalu. Di dalam mendepani cabaran dalam arus Revolusi Industri 4.0, para pendidik perlu lebih terbuka dan bersedia dengan perubahan-perubahan yang mendatang bagi memastikan para-pelajar seterusnya graduan kekal kompeten dan berdaya saing. Mereka perlu kreatif untuk merancang di dalam merekabentuk sesuatu produk dan bijak mencipta potensi daripada $I o T$ bagi diaplikasikan di dalam sesuatu sistem melalui inovasi digital. Kesediaan dan perubahan perlu diambil sebagai langkah mendepani cabaran Revolusi Indutri 4.0. Menurut C. Sheila Rani (2017), Francisco Marmolejo menyatakan bahawa institut pendidikan tinggi perlu lebih fleksibel dan sedia mengharungi cabaran agar tiada golongan masyarakat tidak terpinggir dalam era globalisasi dan digital itu. Sejauh manakah warga pendidik mengambil kisah Pelan Pembangunan Pendidikan (Pendidikan Tinggi) 2015-2025. Dengan gaya pembelajaran yang lebih fleksibel dan secara atas talian, sikap para pendidik perlu lebih berintegriti dan profesional. Para pendidik juga perlu peka dengan keperluan dan minat pelajar agar kaedah pengajaran yang berkesan dapat digunapakai bagi mendapatkan hasil yang diingini.

\section{KESIMPULAN}

Suka atau tidak, peralihan daripada keja-kerja yang biasanya dilakukan oleh manusia kepada robot perlu diterima seiring dengan perkembangan Revolusi Industri 4.0. Perkembangan automasi yang semakin pesat menunjukkan tanda-tanda bahawa dunia pendidikan khasnya perlu beradaptasi demi kelangsungan program dan graduan yang dilahirkannya agar kekal kompeten dan bersedia menempuhi arus Revolusi Industri 4.0 dengan penuh persediaan. Sehubungan dengan itu, untuk kekal kompeten dan berdaya saing, maka persiapan yang rapi haruslah dibuat bagi warga pendidik bagi mendepani cabaran ini. Pendedahan yang meluas kepada tenaga pengajar mampu meningkatkan tahap kesedaran dan pengetahuan terhadap Revolusi Industri 4.0. Dengan ini, transformasi pendidikan dapat dilaksanakan melalui kaedah pengajaran dan pembelajaran dalam menempuhi cabaran ke arah Revolusi Industri 4.0.

\section{DAFTAR PUSTAKA}

Abdullah, Z. (2017). Flipped Classroom Dalam Konteks Malaysia / Konvensyen Antarabangsa Jiwa Pendidik Digital, Mampu Simposium Ke Arah Malaysia Pintar

Afandi Ahmad, A .(2017). Industri 4.0 ubah cara kerja, hidup/ Published by the Higher Education Academy UK Physical Sciences Centre

Ahmad, R; Hassan, H dan Akma, A .(2016). Pembudayaan Kreativiti dan Inovasi Dalam Kalangan Pelajar Institusi Pengajian Tinggi : Kajian Ke atas Pelajar Universiti Malaysia Perlis.

Baker, W.(2000). The "Classroom Flip": Using Web Course Management Tools Too Become The Guide By Buana

Chris, P. (2013). Mooc creators criticise courses' lack of creativity | News | Times Higher

Cormier, D., \& Siemens, G. (2010). Through the Open Door: Open Courses as Research, Learning, and

Yunus,Y. 2017. Merealisasikan Inisiatif Kerajaan Digital ke Arah Negara Pintar Bahagian Kerajaan Educational Research and Reviews. 2017. 8(8), 361-366. Engagement. EDUCAUSE Review, 45,30-39.

Hasan, A; Tuan Mohd Yasin, S.N dan Mohd Yunus, M. F. (2015).Technical Competency for Diploma in Mechatronic Engineering at Polytechnics Malaysia.

Ibrahim. (2007). Ilmu Dan Aplikasi Pendidikan.Bandung : Imtima innovation/invention-andinnovation introduction/content-section-11.6.4 inovasi-atau-pembaharuan.html

Mohd Yusof, M. F.(2017). http://mohdfairuzmohdyusof.blogspot.com/2017/11/industri-40-ir40revolusi.html 
Raja Rahim, R. N .(2017). https://www.hmetro.com.my/mutakhir/2017/09/267141/200000-penuntutseluruh-dunia-manfaatkan-mooc

Rinoto Rin on Wednesday. (2014). http://modelpembelajaransd.blogspot.com/2014/01/pengertianSa'ud, Udin Syaefudin.(2010).Inovasi Pendidikan.Bandung: Alfabeta

Sallabas, M.E. 2013. Analysis of narrative texts in secondary school textbooks in terms of values education.

Selamat, A. R.(1989).Teknologi Sistem Pengajaran.Petaling Jaya : Fajar Bakti

Suyatno.(2009).Menjelajah Pembelajaran Inovatif.Sidoarjo : Pustaka Masmedia

The Side. Paper presented at 11th International Conference on College Teaching and Learning, Jacksonville, FLTom Lemanski, Ruth Mewis and Tina Overton / An Introduction to Work-Based Learning February 2011/

Kementerian Pendidikan Malaysia.(2010).Kreativiti dan Inovasi : Eelemen Merentas Kurikulum KSSR. MalaysiaPembelajaran Abad ke-21 : Trend Integrasi Teknologi 179 Melaka@ Utusan Melayu (M) Bhd1.583711\#ixzz55uxWB2Sh 2014, 11-13 Ogos 2014 